\title{
Nutritional Intakes of Obese Elementary School Children Residing in the Shimokita Peninsula of Aomori, Japan
}

\author{
Takako Kumagai ${ }^{1}$, Yumiko Nakamura ${ }^{1}$, Emi Naijo ${ }^{2}$, Akiko Sugimoto ${ }^{3}$, \\ Barry Kavanagh ${ }^{1}$, Haruyuki Ito ${ }^{1}$ \\ ${ }^{1}$ Aomori University of Health and Welfare, Japan \\ ${ }^{2}$ Department of Health and Welfare, Aomori Prefecture, Japan \\ ${ }^{3}$ Kanagawa Children's Medical Center, Japan
}

\begin{tabular}{l}
\hline \hline Article Info \\
\hline Article history: \\
Received Jul 12, 2014 \\
Revised Aug 20, 2014 \\
Accepted Aug 28, 2014
\end{tabular}

\section{Keyword:}

Childhood Obesity

Dietary survey

Rural

Salt intake

Vegetable

\begin{abstract}
This research examined the lifestyles and eating habits of 42 elementary school fifthgraders (20 boys and 22 girls) over a 3-day period;these childrenresided in the Shimokita Peninsula, Aomori prefecture, which has the highest childhood obesity ratein Japan. The children's nutritional intakeswere recordedvia questionnaires and self-documented meal record diaries over a 3day period (1weekday and the weekend). The meal record diaries recordedwhichmeals the children ate (including snacks) duringthe 3-day period. A regular feature of these children's lifestylewasthe viewing of at least 3 hours of television per day. Compared withthe National Health and Nutrition Survey conducted by the Japanese government, the nutritional and energy intake levels were the same but when we examined food group intakes, the vegetable intake was lower on weekends in comparison to the weekdays when the children were provided school lunches. In addition, salt intake exceeded the recommended standard in more than $80 \%$ of the study sample. We suggest that the pattern of reduced vegetable intake juxtaposed with high salt intake stems from childhood and is repeated and passed down through generations; therefore, the guardians of these children require nutritional guidance and education.
\end{abstract}

Copyright (C) 2014 Institute of Advanced Engineering and Science. All rights reserved.

\section{Corresponding Author:}

Takako Kumagai,

Department of Nutrition,

Faculty of Health Sciences, Aomori University Health and Welfare,

58-1 Mase, Hamadate, Aomori-Shi, 030-8505, Aomori, Japan.

Email: t_kumagai@auhw.ac.jp

\section{INTRODUCTION}

Childhood obesity is an importantpublic healthissue. One in 10 young school-aged children in Japan is considered obese [1],[2]. A revision of lifestyle habits is needed to prevent infant and child obesity, as these conditions lead to an increased risk of high blood pressure, lipid levels, and abnormal glucose tolerance [3]. In the USA,studies have suggested that childrenwhobecome overweight at least once during infancy have a 5-fold higher risk being overweight by the age of 12 [4]. In the UK, reports have suggested that $40 \%$ of individuals who were obese in puberty remained obese into adulthood [5]. These studies show that childhoodobesity can be hugely influential onsubsequent growth in adulthood. Obesity prevention and solutions have become serious talking points in schools. Therefore, it is necessary to improve health and maintain a healthy weight as well as to promote physical activity [6].

In order to grasp the seriousness of the problem of obesity, Japanese national surveys have beenconducted toexamine the physical characteristics of children of both sexes from nursery to high school (aged 5-18 years) [7]. The results of these surveys revealed that with in Japan, the Aomori prefecture has the 
highest number of obese children relative to the national average and that this has been a characteristic of the prefecture formany years [8]. The Shimokita Peninsula within the Aomori prefecture containsthe highest number of obese children and is therefore considered to have the highest number of childhood obesity cases in Japan [8]. However, the reason for this high obesity rate among children in this peninsula is unclear.

Obesity is the accumulation of fat due to energy intake that surpasses energy consumption. Childhood obesity results from eating habits, physical activitylevels, and environmental and hereditary factors that vary according to the region where the children reside.The National Health and Nutrition Survey (NHNS) conducted by the Japanese Ministry of Health, Labor, and Welfare [9] provided an account of Japanese school children's nutritional intakes [10]. The survey, however, utilized random sampling and didnot specifically evaluateobese or rural-dwelling children. In addition, these surveys wereonly conducted over a 1-weekday period. It is therefore difficult to assess food and nutrition intakes over multiple days, including the weekend, and consequently impossibleto evaluate how eating habits correlate with childhood obesity based on the NHNS data. Studies in the literature that evaluated children's eating habits during the weekend have shown that regardless whether the environment was urban or rural, calcium and vegetable intakes were 70-80\% lower than on weekdays when school lunches were eaten [11]-[13]; vitamin B1 intake was also reported to be deficient [14]. These studies suggest that weekday school lunches considerably influence food and nutrition intake. Weekday school lunches aim to give children a good balance of nutrition and food group variation but on the weekend, when school lunch is not eaten, there is a need to investigate the eating habits of children as opposed tomerely on week days with school lunches.

Research involving obese children in rural areas and investigations of their eating habits and lifestyles is not represented in the literature; this research, whichis an investigation of children's eating and lifestyle habits in the Shimokita Peninsula of Aomori prefecture,aims to address that gap. First, the children's meal and food group intakes will be assessed on week days and the weekend, followed by a discussion of how child obesity can be prevented. This research and the evaluation of the children's nutritional intake and lifestyle habit characteristics could benefit health promotion in schools and assist house holds with obesity prevention.

\section{RESEARCH METHOD}

\subsection{The target community}

The population of Aomori has the shortest lifespan of all the 47 prefectures within Japan. Shimokitapeninsula, whichincludes 1city (Mutsu), 1 town (Ooma), and 3 villages (Sai, Kazamaura, and Higashidori), is an area of Aomori located in the remote northeastern cape of the prefecture on the main Japanese island of Honshū. The estimated population is approximately 78,000 people. Retail, wholesale, and administrative services account for the main industries within the region. Mutsu city within Shimokita has an average annual temperature of $9.4^{\circ} \mathrm{C}$ with a maximum temperature of $27.5^{\circ} \mathrm{C}$ in August and a minimum temperature of $-5.4^{\circ} \mathrm{C}$ in January. Annually, the city receives $1297.5 \mathrm{~mm}$ of rain, $70 \mathrm{~cm}$ of snow, and 1675.6 daylight hours. Within the Shimokita area, there is a high percentage of obese childrenand obesity has become a particular problem among infants.

\subsection{The subjects}

With the aid of the Mutsu city Board of Education and the Shimokita Education Administration, cooperation was obtained from 5 elementary schools within the Shimokita peninsula. Upon the advice of these education administrations, fifth graders were selected as the best subjects because at 11 years of age, the students couldself-answer questionnaires; fourth graders were considered too young and sixth graders were in their final year before graduation and considered too busy to participate in the research. The surveys comprised aself-entry dietary and lifestyle survey based on the subjects' lifestyles such the timesat which they get up and eatmeals. The survey also included physical status data such as weights and heights. A meal record diary where in subjects wrote down and took pictures of what they ate over a 3-day period (February to March, 2009) was also conducted.

Of the 151 surveys sent out as outlined above, only 77 guardians and their children signed the research consent form along with the completed dietary and lifestyle survey (a collection rate of $50.9 \%$ ). Of these 77 participants, some only completed 1 or 2 days of the 3-day meal record diary. Therefore,only 42 subjects ( 20 boys and 22 girls) who completed both the self-entrydietary and lifestyle survey andthe full 3day meal record diary were included for analysis within this study. This study was approved by the ethics committee of Aomori University Health and Welfare. 


\subsection{Participants’ physical status}

The physical conditions of the participants were as certained through self-evaluation reports conducted by the subjects. Items within the evaluation included sex, weight, and height. Body mass index (BMI) was calculated based oneach participant's height and weight. The obesity level was determined using criteria stipulated by the Ministry of Education, Culture, Sports, Science, and Technology in Japan, which were based on a school health statistical survey. The obesity classification or level was based on the formula below. Those with anobesity percentage of $\geq 20 \%$ were considered obese; those with a percentage below $20 \%$ were considered underweight.

Obesity level / percentage = Actual body weight $(\mathrm{kg})$-standard (ideal) body weight $(\mathrm{kg})$ according to height $\div$ standard (ideal) body weight criteria $(\mathrm{kg})$ according to height $\times 100$.

Ideal body weight according to height $=a \times$ actual weight $-b$. Coefficients (for 11-year-old subjects): boys, $\mathrm{a}=0.782$ and $b=75.106$; girls, $\mathrm{a}=0.803$ and $\mathrm{b}=78.846$

\subsection{Subjects' lifestyles}

The subjects' lifestyles were measured using a self-entry lifestyle survey that included items such as waking, sleeping, and meal times. Howand at what times the children attended school was also recorded. These times were divided according to the season. The children's activity was measured based on whether they exercised and if so, for how long. In addition, the duration of television viewing, whether they received sufficient sleep, and how often they ate breakfast were also measured. These measured items were similar to those found on physical fitness surveys.

\subsection{Dietary survey (Meal record diary)}

The dietary survey was conducted over a 3-day period. This included 1 week day when the children ate aschool lunch; the remaining 2 days were the weekend, when the children did not attend school or eata school lunch. In a meeting with the children'sguardians, we explained how we wanted the childrento document their 3-day meal records, which included asking them to photograph their meals. If filling out the meal record (of what and when they ate) was difficult for achild, we asked their guardian to help the child fill in everything.

During eachchild's homeroom period at school, the research was explained and research documents given to the children. These documents included the self-entry questionnaires and an explanation of how to write up the 3-day meal diary record as well asa photographic guidethat gave advice regarding the targeted amounts of food and seasoning.

The meal diary record asked the participants to record everything they ate, including snacks, over the 3-day period. An explanation and guide on how to complete the meal record diary was also included. Prior to the start of the study, a pilot test was conducted to help us confirm that a fifth grader would be able to understand and complete the questionnaires and meal diary record. Within the diary, thesubjectshad to fill in the following items: 1) Name of the dish, 2) Ingredients of the dish, 3) Weight of the dish, 4) How the dish was cooked (e.g., boiled, grilled, fried), and 5) The quantity of the uneaten amount (if applicable).

To prevent any omissions within the meal diary record, we asked participants to take photos of the meals (including snacks) that they ate. These photos included the placing of chopsticks and a spoon next to the dish/meal, which provided a scale from which to determine the size of the meal. Participants were asked to take photos of their meals before and after consumption, which allowed for estimations ofthe amount consumed. Forfood dishes that incorporatedseveral typesof ingredients or foods, the food name and weight were measured according to a food service industry guidebook. Altered food weight measurements (e.g., the weight changed after cooking) were corrected to the food weights before cooking. Fordeep fried food dishes, the amounts of absorbed oil were also based on a food service industry guidebook. As the 3-day meal diary record period asked subjects to record their eating habits on a weekday when at school, the school lunch menu was obtained from the school dietician on that day. Usingthe meal diaries and photographs, an estimate of the amount eaten could be obtained. Any leftovers were also recorded viaphotographs.

The nutritional value calculations based on the estimated nutrients, amountsconsumed, and food groupswere conducted using the software packageExcel eiyou kun version 6 (Kenpaku-sha, Tokyo, Japan), and the average intake per day was calculated from theoverall food intake overthe 3days.From the subjects'meal diaries and photographs, the names of the dishes were labeled in a meeting of 5 nationally registered dieticians (from the Aomori Dietetic Association,affiliated with the Nutrition Care Station) who specialized in calculatingnutritionalvalues. After this labeling, an experienced dietician conducted a complete data revision and reviewfollowed by revisions to the food weightsconsumed by the participants. This process was performed in order to prevent any typeof research bias towards the data. 


\section{DATA ANALYSIS}

A descriptive statistical analysis ofthe participants' height, weight, BMI, and nutritional and food group intakes was performed. Nutritional and food group intakes were compared with the results for10-11year-oldchildrenas determined by the NHNS. The NHNS is an annualinvestigation of the subjects' physical conditions, nutritional intakes, and lifestyle factors.

The normally distributed population of the NHNS was compared to the population of this study, and differences between the population mean and the sample mean of this study were also compared. The data in this study were z-transformed under the assumption that the NHNS data were normally distributed. The teststatistic value was calculated fromthe standard normal distribution table.

In addition, to compare and measure the dietary and food group intakes on a weekday, Saturday, and Sunday, a 1-way analysis of variance was conducted followed by a multiple comparisonaccording tothe Bonferroni method. In the complete data analysis we considered adifference to be significant when the null hypothesis was rejected at $\mathrm{p}<0.05$.

\section{RESULT AND DISCUSSION}

\subsection{Physical statuses and living conditions}

In an analysis of the proportionsof the subjects' physical characteristics and obesity levels, anobesitylevel of $\geq 20 \%$ was observedin $5 \%$ of the boys and $13.6 \%$ of the girls, as illustrated in Table 1.In addition, $90 \%$ of the boys' meals were cooked by their mothers or grandmothers, compared with $77.3 \%$ of thegirls' meals. All children walked to schoolin spring and summer andthe majority also walked in winter. Participants noted that it took 14-18 minutes to reach school, although in winter the number of students traveling by cars increased.

Table 1. Characteristics of the subjects

\begin{tabular}{|c|c|c|c|c|}
\hline & $\begin{array}{c}\text { Boys } \\
(n=20)\end{array}$ & $\begin{array}{c}\text { Boys } * \\
(10 \text { years, } n=780)\end{array}$ & $\begin{array}{l}\text { Girls } \\
(\mathrm{n}=22)\end{array}$ & $\begin{array}{c}\text { Girls* } \\
(10 \text { years, } \mathrm{n}=715)\end{array}$ \\
\hline Age (years) & $10.9 \pm 0.4$ & - & $11.0 \pm 0.2$ & - \\
\hline Height $(\mathrm{cm})$ & $144.7 \pm 7.5$ & 139.7 & $148.8 \pm 6.3$ & 142 \\
\hline Weight (kg) & $37.5 \pm 7.0$ & 36.1 & $44.2 \pm 8.8$ & 36.1 \\
\hline BMI $\left(\mathrm{kg} / \mathrm{m}^{2}\right)$ & $17.9 \pm 2.9$ & - & $19.9 \pm 3.2$ & - \\
\hline \multicolumn{5}{|l|}{ Obesity index } \\
\hline Thin $(\leq-20 \%)$ & $1 \quad(5.0)$ & $(1.9)$ & $(0)$ & $(2.4)$ \\
\hline Normal & $18 \quad(90.0)$ & $(83.0)$ & 19 (86.4) & (85.7) \\
\hline Obese $(\geq 20 \%)$ & $1 \quad(5.0)$ & $(15.1)$ & $3 \quad(13.6)$ & $(11.9)$ \\
\hline
\end{tabular}

Data are shown as means \pm standard deviations or n(\%). *Aomori Prefecture School Health Survey, 2012.

Within the sample, only 1 child did not eat breakfast every day. The sleeping durations were $\geq 6 \mathrm{~h}$ for both boys and girls, and approximately $40 \%$ of boys and $50 \%$ of girls reported television viewing durations $\geq 3$ h (Table 2).

\subsection{Three-day average nutrition and food group intakes}

The 3-day averages for the nutritional intake amounts werecompared to the NHNS results as illustrated in Table 3. There were no significant differences in the energy intake amounts between the boys and the girls in this study sample and those in the NHNS. However, among girls from the study sample, sodium intake was significantly different from that reported in the NHNS data $(p<0.05)$. Statistical differences in the calcium intake between both sexes in the current study and the NHNS were minimal $(p<0.05)$. However, among girls, therewere significant differences in the vitamin $\mathrm{D}$ and cholesterol intakes relative to the NHNS data $(p<0.01)$.In addition, niacin intake wasfound to be significantly higher in both genders of the current study sample in comparison to the NHNS data $(p<0.01)$.

Vitamin D intake was significantly higherwithin this study sample $(p<0.01)$, and niacin intake was significantly higher within this sample when compared to male NHNS subjects $(p<0.05)$. Water-soluble dietary fiber, insoluble dietary fiber, and total dietary fiber intakes were significantly higher within our sample in comparison to the NHNS ( $p<0.05,0.01$, and 0.05 , respectively). Salt equivalent intakes differed significantly only between the girls in our study and the NHNS $(p<0.01)$.

Nutritional Intakes of Obese Elementary School Children Residing in The Shimokita .... (Takako Kumagai) 
Tabel 2. Lifestyle

\begin{tabular}{lcc}
\hline & Tabel 2. Lifestyle & Girls $(\mathrm{n}=22)$ \\
\hline Wake-up time & Boys $(\mathrm{n}=20)$ & $6: 08 \mathrm{AM}$ \\
Bedtime & $6: 25 \mathrm{AM}$ & $9: 15 \mathrm{PM}$ \\
Main person who cooks & $9: 16 \mathrm{PM}$ & $2(9.1)$ \\
$\quad$ Father & $0(0)$ & $14(63.6)$ \\
Mother & $14(70.0)$ & $0(0)$ \\
Grandfather & $0(0)$ & $2(9.1)$ \\
Grandmother & $1(5.0)$ & $1(4.5)$ \\
Mother \& Grandmother & $3(15.0)$ & $0(0)$ \\
Oneself & $0(0)$ & $3(13.6)$
\end{tabular}

Attending school means Spring Autum

On foot / minutes

$12(60.0) / 18.3 \pm 10.1$

Bus / minutes

0 ( 0 ) / -

Car / minutes $\quad 4(20.0) / 8.8 \pm 4.1$

Bicycle / minutes

0 ( 0 ) / -

On foot \& Car / minutes $\quad 4(20.0)$ / $11.8 \pm 9.5$

Winter

On foot / minutes

$10(50.0) / 18.0 \pm 8.4$

Bus / minutes

0 ( 0 ) / -

Car / minutes $\quad 5(25.0) / \quad 8.2 \pm 4.2$

Bicycle / minutes

0 ( 0 ) / -

$6+11.5$

18 (81.8) / $13.7 \pm 8.5$

On foot \& Car / minutes

$5(25.0) / 12.6 \pm 11.5$

0 ( 0$)$ / -

3 (13.6) / $5.3 \pm 2.1$

0 ( 0 ) /

1 (4.5) / 35.0

$15(68.2) / 14.9 \pm 9.2$

0 ( 0 ) $/$

$6(27.2) / 5.3 \pm 2.2$

0 ( 0 ) / -

On foot \& Car / minutes

Extracurricular activities or sports clubs

participation

nonparticipation

Exercise other than physical education (frequency)

every day (more than 3days / week)

sometimes $(1 \sim 2$ days / week $)$

often $(1 \sim 3$ days / month $)$

never

Boys * $n=780$

1 (4.5) / 45.0

ercise other than physical education (duration)

$<30$ minutes

$\geq 30$ minutes, $<1$ hour

$\geq 1$ hour, $<2$ hours

$\geq 2$ hours

$18(90.0)$

(81.4)

(18.6)

$17(77.3)$

Girls * $\mathrm{n}=715$

lub activities

Baseball

Basketball

Table tennis

others

2 (10.0)

(75.9)

$11(55.0)$

7 (35.0)

(11.9)

$1(5.0)$

(6.3)

$1(5.0)$

(2.3)

2 (10.0)

(9.5)

3 (15.0)

(12.7)

8 (40.0)

(25.6)

7 (35.0)

(52.2)

(54.4)

(22.7)

(45.6)

10 (55.6)

4 (22.2)

1 (5.6)

3 (16.7)

$-$

17 (77.3)

(54.7)

2 (9.1)

(28.1)

3 (13.6)

(12.7)

0 ( 0$)$

(4.5)

6 (27.3)

1 (4.5)

(28.5)

7 (31.8)

(21.8)

8 (36.4)

(20.4)

(29.2)

Breakfast

everyday

18 (90.0)

2 (10.0)

1 (5.3)

6 (31.6)

$10(52.6)$

$-$

2 (10.5)

sometimes

$0(0)$

(6.7)

19 (86.4)

$2(9.1)$

$1(4.5)$

(8.8)

eeping hours

$<6$ hours

$\geq 6$ hours, $<8$ hours

$0(0) \quad$ (3.6)

$3(15.0) \quad$ (42.7)

$0(0)$

$\geq 8$ hours

17 (85.0)

(53.7)

$11(50.0)$

(4.5)

Watching television (hour / day)

$<1$ hour

$\geq 1$ hour, $<2$ hours

$\geq 2$ hours, $<3$ hours

$2(10.0) \quad(13.8)$

$11(50.0)$

$6(30.0)$

(36.0)

3 (13.6)

4 (20.0)

(24.4)

4 (18.2)

(19.0)

8 (40.0)

(25.8)

4 (18.2)

(30.6)

$\geq 3$ hours

$11(50.0)$

(24.3)

Data are shown as n(\%), (\%), ormeans \pm standard deviations.*Aomori Prefecture School Health Survey 2012.

A comparison of the average food group intake inthis study and the NHNS is shown in Table 4. Comparisons of potato and starch intake revealed small significant difference among the boys within the studies $(p<0.05)$. In our sample, total vegetable intake (green vegetables) was low regardless of $\operatorname{sex}(p<0.01)$. In addition, the overall vegetable intake for both sexes was $150 \mathrm{~g}$, half of the recommended $350 \mathrm{~g}$. In our 
sample, green vegetable intake was low for both sexes, and the 3-day intake oflight-colored vegetables was low $(p<0.05)$. The girls inour sample had a significantly higher intake of eggs $(p<0.01)$. Milk intake was low amongst both sexes within our sample $(p<0.01)$. The boys had a high intake of confectionary foods $(p<0.01)$ and the girls had a low intake of beverages (all non-alcoholic beverages; $p<0.01$ ). Compared with the NHNS data, the girls in our studyhad a significantly higher pantothenic acid intake $(p<0.05)$.

Table 3. Dietary intake over the 3-day period

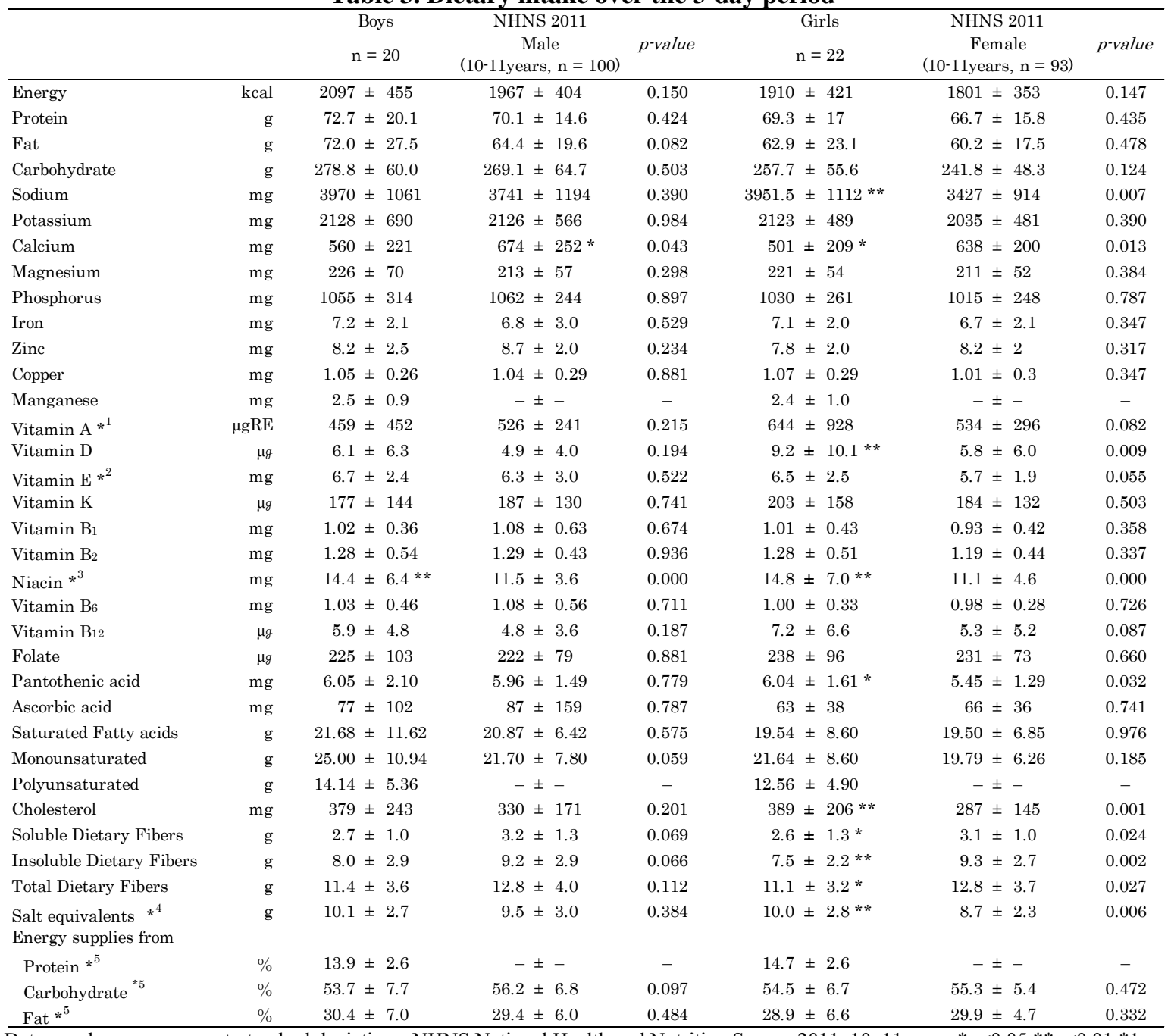

Data are shown as means \pm standard deviations. NHNS,National Health and Nutrition Survey $2011,10-11$ years. $* p<0.05, * * p<0.01 ; * 1$ RE: retinol equivalent, $* 2 \alpha$ - tocopherol, $* 3$ niacin, $* 4$ sodium $\times 2.54 / 100, * 5$ Averagedratio of a personal calculated value. 


\begin{tabular}{|c|c|c|c|c|c|c|c|}
\hline \multirow[b]{3}{*}{ Cereals } & \multirow[b]{3}{*}{$\mathrm{g}$} & \multirow{2}{*}{$\begin{array}{c}\text { Boys } \\
(\mathrm{n}=20)\end{array}$} & \multirow{2}{*}{$\begin{array}{c}\text { NHNS } 2011 \\
\text { Male } \\
(10-11 \text { years, } \mathrm{n}=100)\end{array}$} & \multirow[b]{2}{*}{$p$-value } & \multirow{2}{*}{$\begin{array}{c}\text { Girls } \\
(\mathrm{n}=22)\end{array}$} & \multirow{2}{*}{$\begin{array}{c}\text { NHNS } 2011 \\
\text { Female } \\
(10-11 \text { years, } \mathrm{n}=93)\end{array}$} & \multirow[b]{2}{*}{$p$-value } \\
\hline & & & & & & & \\
\hline & & $410.9 \pm 104.7$ & $440.3 \pm 145.1$ & 1.414 & $401.5 \pm 114.4$ & $390.6 \pm 105.6$ & 0.631 \\
\hline Potatoes and Starches & $\mathrm{g}$ & $36.4 \pm 31.3$ * & $57.7 \pm 48.5$ & 0.049 & $40.4 \pm 43.3$ & $58.6 \pm 47.3$ & 0.238 \\
\hline Sugars and Sweeteners & $\mathrm{g}$ & $7.0 \pm 10.2$ & $4.9 \pm 6.3$ & 0.144 & $6.4 \pm 11.1$ & $5.9 \pm 6.9$ & 0.741 \\
\hline Green Vegetables & $\mathrm{g}$ & $42.4 \pm 39.2 *$ & $70.5 \pm 55.5$ & 0.023 & $46.0 \pm 39.2 *$ & $67.9 \pm 50.3$ & 0.041 \\
\hline Light color Vegetables & $\mathrm{g}$ & $105.9 \pm 90.5$ * & $162.9 \pm 112.0$ & 0.023 & $103.1 \pm 64.8 * *$ & $167.5 \pm 82.7$ & 0.003 \\
\hline Fruits & $\mathrm{g}$ & $82.3 \pm 133.4$ & $91.6 \pm 130.1$ & 0.749 & $64.7 \pm 96.8$ & $72.8 \pm 89.9$ & 0.674 \\
\hline Mushrooms & $\mathrm{g}$ & $7.1 \pm 8.5$ & $10.6 \pm 19.0$ & 0.407 & $7.0 \pm 13.8$ & $12.3 \pm 18.8$ & 0.184 \\
\hline Algae & $\mathrm{g}$ & $5.0 \pm 19.7$ & $9.1 \pm 19.0$ & 0.177 & $5.7 \pm 12.8$ & $7.6 \pm 15.5$ & 0.555 \\
\hline Beans & $\mathrm{g}$ & $29.5 \pm 35.9$ & $31.0 \pm 39.9$ & 0.857 & $33.7 \pm 38.7$ & $45.8 \pm 57.7$ & 0.327 \\
\hline Fats and Oils & $\mathrm{g}$ & $11.6 \pm 9.1$ & $11.2 \pm 8.7$ & 0.849 & $11.6 \pm 7.4$ & $9.1 \pm 6.3$ & 0.067 \\
\hline Confectioneries & $\mathrm{g}$ & $65.3 \pm 77.1 *$ & $33.4 \pm 46.8$ & 0.002 & $36.4 \pm 56.1$ & $36.6 \pm 47.4$ & 0.984 \\
\hline Beverage & $\mathrm{g}$ & $184.1 \pm 239.2$ & $290.6 \pm 289.7$ & 0.101 & $162.0 \pm 206.8 * *$ & $334.8 \pm 282.9$ & 0.004 \\
\hline Seasonings & $\mathrm{g}$ & $47.6 \pm 38.5$ & $82.0 \pm 73.4$ & 0.582 & $51.7 \pm 28.5$ & $57.3 \pm 29.3$ & 0.373 \\
\hline
\end{tabular}

Data are shown as means \pm standard deviations. NHNS, National Health and Nutrition Survey 2011. ${ }^{*} p<0.05,{ }^{* *} p<0.01$

Table 5. Boys'nutritional intakeson the weekday, Saturday, and Sunday

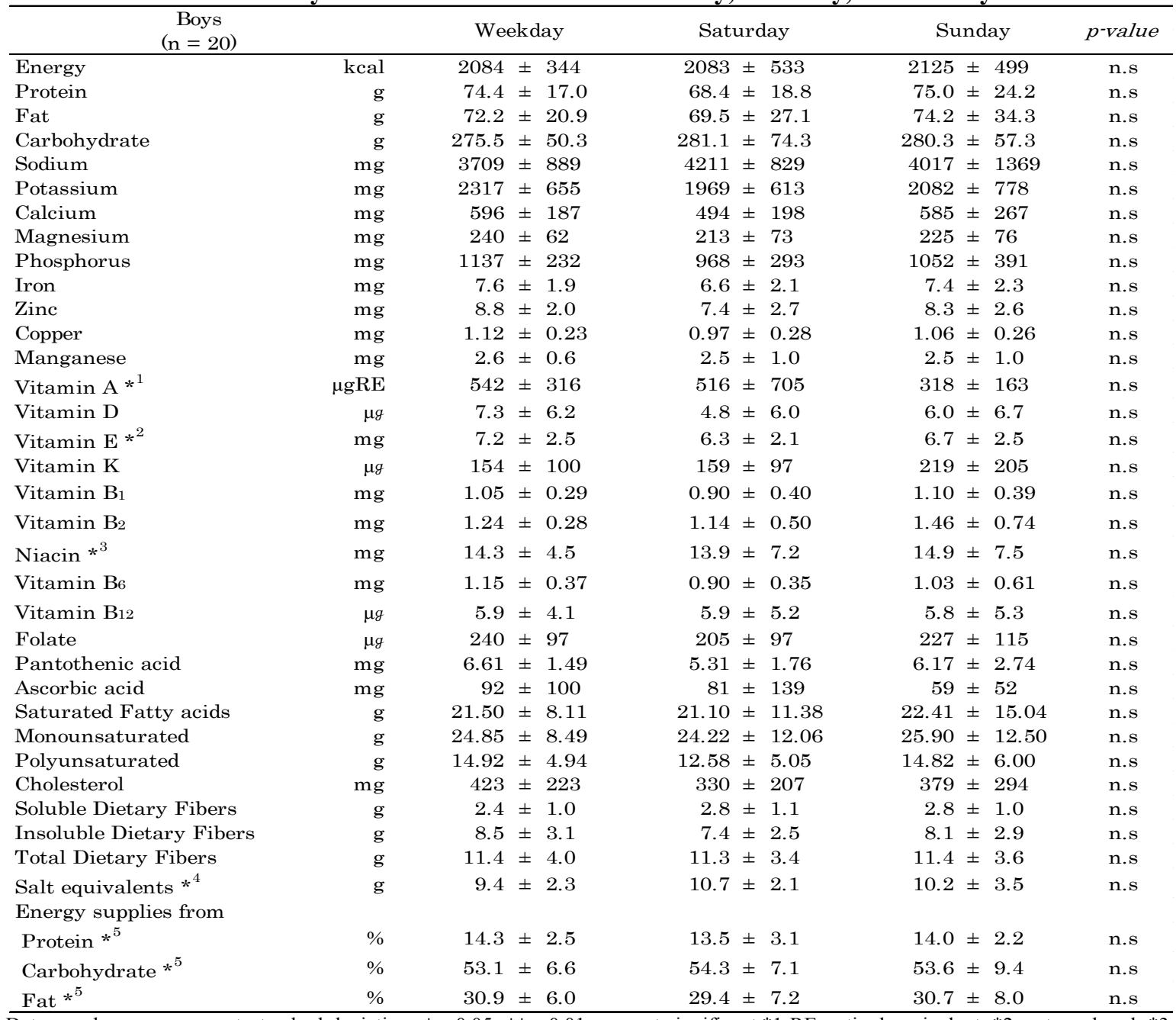

Data are shown as means \pm standard deviations. ${ }^{*} p<0.05,{ }^{* *} p<0.01$,n.s.: not significant. ${ }^{*} 1$ RE: retinol equivalent, ${ }^{*} 2 \alpha-$ tocopherol, ${ }^{* 3}$ niacin, *4 sodium $\times 2.54 / 100, * 5$ Averaged ratio of a personal calculated value. Weekday, Saturday,andSundayintakes were analyzed via1-wayanalysis of variance(multiple comparison,Bonferroni). 


\subsection{Comparison of food intakes on the weekday and the weekend}

Comparisons of the nutritional intakes are shown in Table 5 (boys) and Table 6 (girls). Intakes according to food group on the weekday and the weekend are shown in Table 7. In each category, there was no statistical difference between the boys and girls. However, a tendency toward increased salt intake on the weekend relative to the week day was observed. Among boys, total vegetable and green and light-colored vegetable intakes were slightly significantly higher on Sunday than on the weekday $(\mathrm{p}<0.05)$. Among girls, fish and shellfish intake was slightly and significantly higher on Sunday than the weekday $(\mathrm{p}<0.05)$. Among boys, egg intake was lower on Saturday than on the weekday $(\mathrm{p}<0.05)$, and milk intake was lower on Sunday than on the weekday $(p<0.05)$. Among girls, fat and oil intake increased significantly on Saturday compared withthat on the weekday $(\mathrm{p}<0.05)$. Although there was no difference between the boys and girls, there was a tendency toward increased beverage and confectionary intake on the weekend in comparison to the week day.

Table 6. Girls'nutritional intakeson the weekday, Saturday, and Sunday

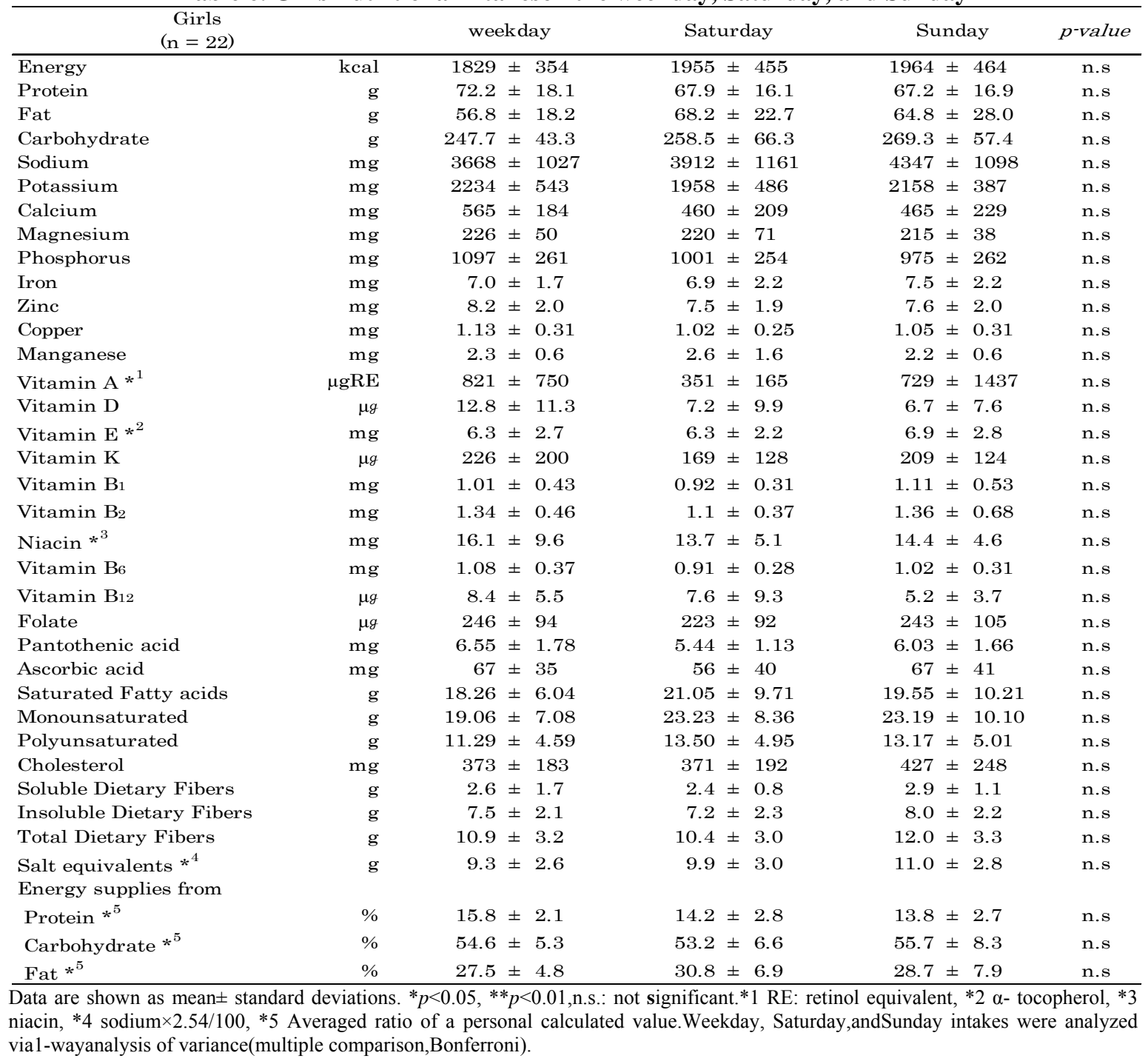

Nutritional Intakes of Obese Elementary School Children Residing in The Shimokita .... (Takako Kumagai) 
Table 7. Intakes according to food groups on the weekday, Saturday, and Sunday

\begin{tabular}{|c|c|c|c|c|c|}
\hline \multirow[b]{3}{*}{ Cereals } & \multirow[b]{3}{*}{$\mathrm{g}$} & \multicolumn{4}{|c|}{ Boys $(n=20)$} \\
\hline & & weekday & Saturday & Sunday & \multirow{2}{*}{$\frac{p \text {-value }}{\text { n.s }}$} \\
\hline & & $388.4 \pm 102.1$ & $442.2 \pm 104.0$ & $404.9 \pm 105.9$ & \\
\hline Potatoes and Starches & $\mathrm{g}$ & $49.9 \pm 29.7$ & $27.6 \pm 31.0$ & $30.6 \pm 29.9$ & n.s \\
\hline Sugars and Sweeteners & $\mathrm{g}$ & $5.0 \pm 4.7$ & $8.4 \pm 13.8$ & $7.6 \pm 10.7$ & n.s \\
\hline Nuts and Seeds & $\mathrm{g}$ & $1.7 \pm 3.1$ & $0.4 \pm 0.8$ & $3.0 \pm 6.9$ & n.s \\
\hline Vegetables & $\mathrm{g}$ & $197.4 \pm 110.3$ & $137.2 \pm 74.9$ & $107.3 \pm 115.9 *$ & 0.020 \\
\hline Green Vegetables & $\mathrm{g}$ & $61.7 \pm 47.7$ & $33.8 \pm 33.8$ & $30.2 \pm 25.6 *$ & 0.026 \\
\hline Light color Vegetables & $\mathrm{g}$ & $135.7 \pm 85.0$ & $103.5 \pm 63.4$ & $77.1 \pm 110.4$ & n.s \\
\hline Fruits & $\mathrm{g}$ & $90.0 \pm 139.7$ & $75.8 \pm 114.6$ & $80.3 \pm 148.9$ & n.s \\
\hline Mushrooms & $\mathrm{g}$ & $10.0 \pm 8.8$ & $6.0 \pm 8.6$ & $5.1 \pm 7.7$ & n.s \\
\hline Algae & $\mathrm{g}$ & $1.8 \pm 3.3$ & $12.4 \pm 34.2$ & $1.4 \pm 2.3$ & n.s \\
\hline Beans & $\mathrm{g}$ & $31.8 \pm 29.3$ & $23.9 \pm 19.6$ & $32.3 \pm 51.9$ & n.s \\
\hline Fishes and Shellfishes & $\mathrm{g}$ & $69.7 \pm 55.7$ & $61.1 \pm 58.6$ & $50.6 \pm 49.9$ & n.s \\
\hline Meats & $\mathrm{g}$ & $94.1 \pm 57.3$ & $88.8 \pm 63.6$ & $101.4 \pm 71.1$ & n.s \\
\hline Eggs & $\mathrm{g}$ & $52.3 \pm 38.2$ & $34.4 \pm 39.0^{*}$ & $43.5 \pm 49.3$ & 0.033 \\
\hline Milks & $\mathrm{g}$ & $270.0 \pm 118.0$ & $152.4 \pm 112.0$ & $176.1 \pm 182.5$ & n.s \\
\hline Fats and Oils & $\mathrm{g}$ & $12.0 \pm 7.7$ & $9.6 \pm 7.6$ & $13.1 \pm 11.5$ & n.s \\
\hline Confectioneries & $\mathrm{g}$ & $34.3 \pm 42.2$ & $74.2 \pm 77.7$ & $89.4 \pm 95.4$ & n.s \\
\hline Beverage & $\mathrm{g}$ & $115.3 \pm 156.9$ & $229.9 \pm 311.4$ & $212.7 \pm 227.2$ & n.s \\
\hline \multirow[t]{3}{*}{ Seasonings } & $\mathrm{g}$ & $52.6 \pm 24.4$ & $42.2 \pm 19.9$ & $47.5 \pm 59.6$ & n.s \\
\hline & & \multicolumn{4}{|c|}{ Girls $(n=22)$} \\
\hline & & weekday & Saturday & Sunday & $p$-value \\
\hline Cereals & $\mathrm{g}$ & $368.7 \pm 123.6$ & $403.8 \pm 91.8$ & $440.0 \pm 116.9$ & n.s \\
\hline Potatoes and Starches & $\mathrm{g}$ & $53.3 \pm 51.8$ & $31.7 \pm 29.5$ & $33.3 \pm 42.0$ & n.s \\
\hline Sugars and Sweeteners & $\mathrm{g}$ & $6.3 \pm 6.1$ & $9.1 \pm 17.6$ & $3.6 \pm 6.0$ & n.s \\
\hline Nuts and Seeds & $\mathrm{g}$ & $0.2 \pm 0.7$ & $2.4 \pm 6.5$ & $0.1 \pm 0.3$ & n.s \\
\hline Vegetables & $\mathrm{g}$ & $162.1 \pm 79.4$ & $127.3 \pm 76.8$ & $155.6 \pm 53.6$ & n.s \\
\hline Green Vegetables & $\mathrm{g}$ & $55.7 \pm 41.3$ & $35.7 \pm 33.6$ & $44.5 \pm 40.9$ & n.s \\
\hline Light color Vagetables & $\mathrm{g}$ & $106.4 \pm 71.7$ & $91.6 \pm 67.0$ & $111.1 \pm 54.3$ & n.s \\
\hline Fruits & $\mathrm{g}$ & $59.6 \pm 98.1$ & $68.4 \pm 93.1$ & $67.3 \pm 103.6$ & n.s \\
\hline Mushrooms & $\mathrm{g}$ & $8.1 \pm 8.7$ & $7.0 \pm 18.0$ & $5.6 \pm 14.7$ & n.s \\
\hline Algae & $\mathrm{g}$ & $3.2 \pm 6.1$ & $7.6 \pm 18.2$ & $6.7 \pm 12.3$ & n.s \\
\hline Beans & $\mathrm{g}$ & $36.2 \pm 39.6$ & $37.3 \pm 46.9$ & $26.9 \pm 27.7$ & n.s \\
\hline Fishes and Shellfishes & $\mathrm{g}$ & $81.3 \pm 46.3$ & $63.9 \pm 74.8$ & $38.1 \pm 38.4 *$ & 0.034 \\
\hline Meats & $\mathrm{g}$ & $67.1 \pm 41.1$ & $72.8 \pm 46.0$ & $82.3 \pm 49.2$ & $\mathrm{n} . \mathrm{s}$ \\
\hline Eggs & $\mathrm{g}$ & $39.9 \pm 37.1$ & $46.4 \pm 33.4$ & $56.8 \pm 42.1$ & n.s \\
\hline Milks & $\mathrm{g}$ & $253.4 \pm 139.9$ & $146.9 \pm 167.1$ & $117.7 \pm 134.2 * *$ & 0.009 \\
\hline Fats and Oils & $\mathrm{g}$ & $8.3 \pm 6.5$ & $14.4 \pm 6.6^{*}$ & $12.6 \pm 8.0$ & 0.013 \\
\hline Confectioneries & $\mathrm{g}$ & $28.0 \pm 48.7$ & $29.5 \pm 53.3$ & $54.2 \pm 65.6$ & $\mathrm{n} . \mathrm{s}$ \\
\hline Beverage & $\mathrm{g}$ & $96.2 \pm 160.2$ & $217.0 \pm 243.7$ & $186.7 \pm 204.1$ & n.s \\
\hline Seasonings & $\mathrm{g}$ & $48.7 \pm 20.0$ & $47.7 \pm 27.2$ & $59.8 \pm 37.2$ & n.s \\
\hline
\end{tabular}

This paper describes the first research to examine the rural Shimokita peninsula in Japan, where the childhood obesity rate is particularly high. The obesity rates were recorded at $13.6 \%$ for girls and $5 \%$ for boys. According to the annual report of School Health Statistics Research, among elementary school fifth graders, the obesity rates were $10.9 \%$ for boys and $8 \%$ for girls [8]; therefore, the rate for our sample of girls exceeded the national average. In addition, even when compared with the $11.9 \%$ overall obesity rate of children in the Aomori prefecture [10], the obesity rate of our sample of girls remained high.

Lifestyle is a contributing factor to obesity. Regarding the children's physical activity levels, most walked to school although the number of those traveling to school by car increased in winter. According to the literature, $50-80 \%$ of children who reside in rural areas use cars to attend school [12],[13] but within our sample, therate was $14-27 \%$; therefore, we cannot say that the number of children traveling to school by car was particularly high. In addition, it took the children in our sample 14-18 minutes to walk to school but within rural areas where children are taken to school by car, the time required to walk that distance is 5 minutes [15] or approximately 15 minutes less than the children's commute in our study. According to the Japanese Society of School Health surveillance survey, the average duration for a 1-way journey on foot to school for elementary fifth and sixth graders was 16-17 minutes [16], which does not surpass the longest time of 18 minutes reported within the current study sample. 
Gotet al. [17] showed that within large school districts, the commuting distances are long, resulting in the tendency to take children to school by car, which in turn leads to a higher obesity rate. Heelan et al.[18] reported that the main factor leading children to be driven to school as opposed to walking was the distance involved. Within this study, however, because the commuting distances and school district scales were not examined, it is not known whether the factors outlined byHeelan et al.[18] influenced the parents to take their children to school by car.

The data within this study and in surveys on children's physical activity in communities within southern Aomori prefecture showed that children walked less onthe weekend than on school weekdays. A previous survey reported that for $25 \%$ of children, their walking distances were reduced by $>50 \%$ on weekends relative to week days [19].

The combination of reduced walking on the weekend and traveling to school by car can lead to lower levels of physical activity in children. To increase physical activity, we suggest that even if children are driven to school, when they are picked up, they should be made to walk to where their guardian will meet them rather than being picked up directly in front of the school. This would providethe child with a slight increase in physical activity.

Apart from comminuting to school, the children were also involved in other physical activities. The number of children who belonged to sports clubs and performed exercise on a regular basis outside of physical education classes was higher than the prefecture average; however, the television viewing duration exceeded 3 hours perday, a particularly high level. It has been suggested that long television viewing durations are associated with a higher obesity rate [20]; therefore, reducing the amount of television viewing is considered an effective measure for reducing obesity [21].

There were no great differences in nutritional intakes between the reported NHNS data for10-11year-old and the data obtained during this study, but there were differences in calorie intake based on the national nutrition criteria that stipulate the necessary caloric intake for 10-11-year-olds. The intakes of children inthe current sample were below the standards of 2,250 calories for 10-11-year-oldboys and 2,000 calories for10-11-year-old girls.

The fat energy and carbohydrate energy ratios (\%) were within the standard ranges. When compared with nutritional surveys of the energy intakes of elementary school fifth graders, our study sample reported the same energy intake levels; therefore, we cannot say that our sample's intake was particularly high. The lack of calcium intake within the sample is a reflection of nation wide calcium deficiency. Low calcium intake on non-school days when school lunch was not consumed has also been reflected in other studies [11],[12]. Calcium is essential for future bone growth and osteoporosis prevention, and its intake is strongly encouraged.

The salt intake levels ofour sample exceeded the recommended levels of $8 \mathrm{~g}$ for boys and $7.5 \mathrm{~g}$ for girls. 17of the boys $(85 \%)$ and 19 of the girls $(86.4 \%)$ were over the recommended levels. Taken together, $80 \%$ of the total sample exceeded the recommended salt intake. This high salt intake could be attributed to the frequency of instant noodle consumption. The salt contentsoffast food were also considered, but only 2 boys $(10 \%)$ and 2 girls $(9.1 \%)$ ate fast food during the study period and as only 4 participants ate fast food, it would be difficult to make assumptions. On the other hand, 7 boys (35\%) and 5 girls $(22.7 \%)$ reported instant noodle consumption. To change the custom of eating heavily seasoned, high-calorie food [22], the children's guardians must be instructed to initiate a new habit of serving children lightly seasoned dishes with low salt contents. According to the Aomori prefecture Community Survey, the salt intake levels of school children who reside in rural areas exceeded the national average. This finding was reflected in the current study, and it is felt that although salt intake was not considered a contributing factor to obesity in this study, this factor should be considered in future studies.

Within our sample, vegetable intake was very low; on the weekend when school lunch was not provided, the participants consumed $100-120 \mathrm{~g}$ of vegetables, including $30-40 \mathrm{~g}$ of dark green and yellow vegetables. According to the literature, the non-school-lunch day vegetable intake is $200 \mathrm{~g}$ [14]. According to the Aomori Prefecture Health and Nutrition Survey, the daily vegetable intake was 250g among 7-14-yearolds [10], which is $50 \%$ more than the vegetable intake of our study participants.Onereason for this low vegetable intake might be the fact the long-term average regional vegetable intake has always been low, and this fact influences younger generations [23]-[27]. We would like to see greater incorporation of vegetables in the meals preparedby the children's guardians and for increased vegetable intake to become a regular eating habit. In adults, vegetable consumption is known to reduce the risk of obesity, cancer, and chronic disease; however, the relationship between vegetable intake and obesity prevention among children remains largely unknown. Some studies have shown that when comparing obeseand non-obese children residing in rural areas, the obese children consume more vegetables [28]. Reports have shown that people who consume vegetables, fruits, fish, and cereals are more likely to have low blood pressure [29]. A balanced meal is therefore desirable.

Nutritional Intakes of Obese Elementary School Children Residing in The Shimokita .... (Takako Kumagai) 
The limitations ofthis study include the fact that the survey collection return rate was low, which might account for the low rate of obesity within this sample. Therefore, the evidence presented herein cannot be used to accurately predict obesity within this region. The reasons for this low collection return rate could include a failure of the children's guardians to acknowledge that their children were overweight or obese and consequently to avoid completing the questionnaires. Studies have shown that the self-entry survey participation rates are considerablylower among guardians of overweight children than amongguardiansof non-obese children [30]. Therefore, although the questionnaires were anonymous, the participants may not have had the confidence or willingness to allow their children to be perceived as obese or themselves to be perceived as failing to cook healthy meals. In hindsight, we also should have includeda second week day that included the child's school lunch for balance, along with the 2 weekend days.

This study has attempted to reportthe nutritional and food group intakes of children residing in the Shimokita Peninsula, Aomori prefecture, Japan. This area has the highest rate of childhood obesity, which until now has not been clarified within the literature. Obesity prevention in this area needs to be addressed, and we suggest that the children walk to school, increase their physical activity levels, and limit their television viewing. In terms of food intake, vegetable consumption should be increased and salt intake decreased.

\section{CONCLUSION}

The Shimokita Peninsula has the highest rate of child obesity in Japan, and this study aimed to examine the nutritional intakes of these children using questionnaires and self-documented meal record diaries. The viewing of $\geq 3$ hours of television per day was a regular feature of these children's lifestyles. Compared with theNHNS data, the nutritional and energy intake levels in our sampledid not differ; however, when we examined the food group intakes, the vegetable intake in our sample was lower on weekends than on the weekday, when the children consumed a school lunch. Additionally, the salt intake level exceeded the recommended standard in $>80 \%$ of the study sample. We suggest that the low vegetable intake juxtaposed with the high salt intake stems from childhood and comprises apattern that is repeated and passed down through the generations; therefore, nutritional guidance and education should be provided to the guardians of these children.

\section{ACKNOWLEDGEMENTS}

This study was conductedwith the aid and cooperation of the Aomori University Health and Welfare research center, led by Yumiko Nakamura. We also would like to thank the Mutsu city Board of Education, the Office of the Department of Health and Welfare for the Citizens of Shimokita, the elementary schools of the Shimokita area, and the children and guardians who were involved in the study. Finally, we thank the Aomori Dietetic Association, which isaffiliated with the Nutrition Care Station, for their cooperation as well asthe Public Interest Incorporated Association.

\section{REFERENCES}

[1] Murata, M., "Income distribution and cause-specific mortality", Japanese Journal of Pediatric Medicine, vol/issue; 38(9), pp.1528-1534, 2006.

[2] Matsushita, Y., Yoshiike, N., Kaneda, F., Yoshita, K., Takimoto, H., "Trends in childhood obesity in Japan over the last 25 years from the national nutrition survey", Obesity Research, vol/issue: 12(2), pp. 205-214, 2004.

[3] Klish,W.J., "Childhood obesity: Pathophysiology and treatment", Pediatrics International, vol/issue: 37(1), pp. 1-6, 1995.

[4] Nader, P.R., O'Brien, M., Houts, R., et al., "Identifying risk for obesity in early childhood", Pediatrics, vol/issue: 118(3), pp. 594-601, 2006.

[5] Power, C., Lake, J.K., Cole, T.J., "Body mass index and height from childhood to adulthood in the 1958 British born cohort", The American Journal of Clinical Nutrition, vol/issue: 66(5), pp. 1094-1101, 1997.

[6] Ministry of Health, Labour, and Welfare, "Health Japan (the second term)", 2013.

[7] Ministry of Education, Culture, Sports, Science, and Technology, "School Health Statistics", 2012.

[8] Aomori Prefectural Government Board of Education, "Health and Physical Fitness of Children and Students", 2012.

[9] Ministry of Health, Labour, and Welfare, "National Health and Nutrition Survey", 2013.

[10] Aomori Prefectural Government Department of Health and Welfare, "Aomori Prefecture Health and Nutrition Survey Results and Dental Disease Survey Results", 2013.

[11] Nishi,M., "Intake of calcium, vegetables and milk products in weekdays and holidays by school children", Japanese Society of Child Health, vol/issue: 70(1), pp. 3-7, 2011.

[12] Itoi, A., Tanaka, Y., Kimura, M., "A Survey of the activity level and nutritional intakes in 4th-6th graders of an agricultural area", Japanese Journal of School Health, vol/issue: 45(5), pp. 454-464, 2003. 
[13] Itoi, A., Tanaka, Y., Kimura, M., "A survey of the activity level and nutritional intakes of 4th-6th graders in an agricultural area of the Tohoku district", Japan Society of Physical Anthropology, vol/issue: 10(2), pp. 79-84, 2005.

[14] Nozue, M., Jun, K., Ishihara, Y., Takeda, Y., Nagai, N., Yoshita, K., Ishida, H., "Differences in food consumption and distribution of meals between the days with or without school lunches among $5^{\text {th }}$ grade elementary school students", The Japanese Journal of Nutrition and Dietetics, vol/issue: 68(5), pp. 298-308, 2010.

[15] Itoi, A., Adachi, M., Satoh, I., Kimura, M., "In the case of obesity and the active mass of the child in the farm village area with many privately-owned car pickup and dietary habits (I Elementary School)", Journal of Japan Society for the Study of Obesity, vol/issue: 13(1), pp. 51-59, 2007.

[16] Japanese Society of School Health, "Heisei 20 nendo The surveillance business report of a child and the student", pp. $51,2010$.

[17] Goto, A., Koizumi, H., Komatsu, K., Nishinomiya, F., Takahashi, I., Ikeda, K., Akabane, M., Sawaguchi, H., Inaba, Y., Ohno, T., "10-Year-Study of obese school children in Akita city", The Journal of the Japan Pediatric Society, vol/issue: 108(12), pp. 1473-1478, 2004.

[18] Heelan, K.A., Donnelly, J.E., Jacobsen, D.J., Mayo, M.S., Washburn, R., "Active commuting to and from school and BMI in elementary school children-preliminary data", Child Care Health and Development, vol/issue: 31(3), pp. 341-349, 2005.

[19] Takahiro, M., Tomoko, B., Michiko, K., Kiyoshi, S., "Activity among children on holidays in a small town in the Tohoku district", Journal of Physiological Anthropology, vol/issue: 29(2), pp. 59-64, 2010.

[20] Gortmaker, S.L., Must, A., Sobol, A.M., Peterson, K., Colditz, G.A., Dietz, W.H., "Television viewing as a cause of increasing obesity among children in the United States, 1986-1990", Archives of Pediatric and Adolescent Medicine, vol/issue: 150(4), pp. 356-362, 1996.

[21] Gortmaker, S.L., Cheung, L.W., Peterson, K.E., Chomitz, G., Cradle, J.H., Dart, H., Fox, M.K., Bullock, R.B., Sobol, A.M., Colditz, G., Field, A.E., Laird, N., "Impact of a school-based interdisciplinary intervention on diet and physical activity among urban primary school children: eat well and keep moving", Archives of Pediatric and Adolescent Medicine, vol/issue: 153(9), pp. 975-983, 1999.

[22] Benton, D., "Role of parents in the determination of the food preferences of children and the development of obesity", International Journal of Obesity and Related Metabolic Disorders, vol/issue: 28(7), pp. 858-869, 2004.

[23] Aomori Prefectural Government Department of Environmental Health, "Citizen of the Prefecture Dietary Habits Working Papers (Showa 61 nen)", pp. 9, 1987.

[24] Aomori Prefectural Government Department of Environmental Health, "Citizen of the Prefecture Dietary Habits Working Papers (Heisei 3 nen)", pp. 15, 1992.

[25] Aomori Prefectural Government Department of Community-based Welfare, "A Citizen of the Prefecture Nutrition Survey Report(Heisei 8 nen)", pp. 12, 1998.

[26] AomoriPrefectural Government Department of Healthy Medical Care, "Heisei 13 nen Health Survey Results", pp. $108,2006$.

[27] Aomori Prefectural Government Department of Health and Welfare, "Heisei 17 nen Aomori Prefecture Health and Nutrition Survey", pp. 48, 2006.

[28] Tovar, A., Chui, K., Hyatt, R.R., Kuder, J., Kraak, V.I., Choumenkovitch, S.F., Hastings, A., Bloom, J., Economos, C.D., "Healthy-lifestyle behaviors associated with overweight and obesity in US rural children", BMC Pediatrics, vol/issue: 12(102), pp. 1-10, 2012.

[29] McNaughton, S.A., Ball, K., Mishra, G.D., Crawford, D.A., "Dietary patterns of adolescents and risk of obesity and hypertension", Journal of Nutrition, vol/issue: 138(2), pp. 364-370, 2008.

[30] Strauss R.S., "Childhood obesity and self-esteem", Pediatrics, vol/issue: 105(1), pp. 15, 2000. 